Military Technical College Kobry El-Kobbah, Cairo, Egypt.

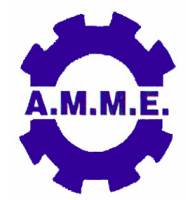

$15^{\text {th }}$ International Conference on Applied Mechanics and Mechanical Engineering.

\title{
DYNAMIC BEHAVIOUR OF PAPER HONEYCOMB SANDWICH PANELS
}

\author{
M. R. Said ${ }^{*}$, M. K. Ismail ${ }^{* *}$ and H. Md Akil ${ }^{* *}$
}

\begin{abstract}
Low velocity impact tests have been conducted on paper honeycomb sandwich panels. Two panel thicknesses with span length of $100 \mathrm{~mm}$ are used; these are 35 $\mathrm{mm}$ and $41 \mathrm{~mm}$, respectively. The dynamic behavior of each paper honeycomb thickness is investigated using two types of indentors: hemispherical and bar. The effect of indentor, and specimen length are studied. This includes the pattern of loaddisplacement curve collapse load and energy absorbed. It concludes that the dynamic collapse load on $41 \mathrm{~mm}$ thickness for hemispherical indentor increases by $5 \%$ compared with $35 \mathrm{~mm}$. The impact energy absorbed for hemispherical indentor increases by $36 \%$.
\end{abstract}

\section{KEYWORDS}

Low velocity impact, paper honeycomb sandwich panel, dynamic loading.

Professor, Faculty of Mech. Engineering, Universiti Teknikal Malaysia Melaka, Malaysia.

** Postgraduate Student, Faculty of Mech. Eng., Univ. Teknikal Malaysia Melaka, Malaysia. Associate Professor, School of Material and Mineral Resources Eng., Engineering Campus, Universiti Sains Malaysia, Malaysia. 


\section{INTRODUCTION}

A sandwich structured composite is a special class of composite materials that is fabricated by attaching two thin but stiff skins to a lightweight but thick core. The core material is normally low strength material, but its higher thickness provides the sandwich composite with high bending stiffness with overall low density. The separation of the skins by the core increases the moment of inertia of the panel with little increase in weight, producing an efficient structure for resisting bending and buckling loads. The strength of sandwich panels depends on the size of the panel, facing material used and the number or density of the honeycomb cells within it. Honeycomb composites are used widely in many industries, from aerospace industries, automotive and furniture to packaging and logistics.

Sandwich panels with honeycomb cores have been studied by many researchers. Yang and Qiao [1] have done a quasi-static indentation behavior of honeycomb sandwich materials which applied in impact simulations and found that the corresponding global stiffness changes in the load versus displacement curve clearly depict the three loading stages of failure process (i.e., initial core yielding load, global transition load, and ultimate failure load). The honeycomb panels offer high strengthto-weight ratio and are produced in thicker panels than the conventional wood-based panels [2].

Crupi and Montaini [3] performed static and dynamic three-point bending on aluminium foam sandwich to determine the collapse modes of the panels. From their study, three different collapse modes (Modes I, IIA and IIB) can be obtained depending on the support span distance and on the own properties of Aluminium Foam Sandwich (AFS) panels. Paik et. al. [4] has studied the strength characteristics of aluminium honeycomb sandwich panels using a series of strength tests, namely three-point bending tests, buckling/collapse tests and lateral crushing tests. They also carried out a theoretical study to analyze the elasto-plastic bending behavior, buckling/ultimate strength and crushing strength of sandwich panels subject to the corresponding load component.

Herup and Palazotto [5] investigated the low velocity impact and static indentation test on sandwich plates to characterize damage initiation as a function of facesheet thickness and loading rate. This research is to compare the damage when using static indentation test and impact test. Static indentation test show damage that is similar to that produced by low-velocity impact.

The mechanical behaviour of a sandwich panel depends on the properties of the face and core materials and on its geometry. In most applications the panel must have some required minimum stiffness, it must not fail under some maximum service loading and it must be as light as possible [6]. Its design of load can be formulated as an optimization problem and the goal is the panel with minimum weight which meets the constraints on stiffness and strength. The optimization can be carried out with respect to the core and skin thicknesses, with respect to the core and skin materials and with respect to the core density. 
Hazizan and Cantwell [7-8] are investigated the low velocity impact response for aluminium honeycomb and foam based sandwich structures using an instrumented falling-weight impact tower. The rate-sensitivity of the specimen was investigated through the series of flexure, shear and indentation tests. The impact response test resulted in a number of different failure modes, energy absorbed in bending, shear and contact effects. It has been shown that a simply energy-balance model based on the dissipation of energy during the impact can be used.

The objective of this study is to investigate the dynamic behavior of collapse load and energy absorbed of sandwich panels with $35 \mathrm{~mm}$ and $41 \mathrm{~mm}$ thickness, using two types of indentors, under low velocity impact and compared with quasi-static loading [9].

\section{EXPERIMENTAL WORK}

\section{Specimen Preparation}

One type of paper honeycomb sandwich panels with different thicknesses has been investigated. The paper honeycomb sandwiches (PHS) are supplied in the form of large panels. These panels are made of lightweight Kevlar paper $\mathrm{HRH}-36$ honeycomb core and AGP280-5H woven carbon prepregs. The $0.6 \mathrm{~mm}$ thick composite skins in the sandwich structures were based on a carbon/ epoxy composite laminates. The samples dimensions are $150 \mathrm{~mm} \times 50 \mathrm{~mm} \times t$, where $t=$ thickness of sandwich panels as shown in Fig.1. Two thicknesses of paper honeycomb sandwiches are selected: $35 \mathrm{~mm}$ and $41 \mathrm{~mm}$.

The samples dimension also follow the ASTM International standard (C 393-00) that state the test specimen will have a rectangular cross section. The standard states that the depth of the specimen shall be equal to the thickness of sandwich construction and the width shall be not less than twice the total thickness not less than three times the dimension of a core cell, not greater than one half the span lengths.

\section{Experimental Procedure}

The experiments were mostly conducted at the School of Material And Mineral Resources Engineering, Engineering Campus, Universiti Sains Malaysia. Impact test were conducted using instrumented falling-weight impact tower as shown in Fig.2(a). The impact force was measured using a Kistler 9333A piezo-electric load cell located just above the indentor head of the impactor and variation of this signal with time was recorded by a dedicated computer. The specimens were supported on two 10 $\mathrm{mm}$ diameter steel cylinders positioned on movable right angle supports as shown in Fig. 2(b). The support span for this experimental are fixed at $100 \mathrm{~mm}$.

Two indentors are used for the impact test; these are hemispherical and bar indentors as shown in Figs. 3(a) and 3(b), their weights are $2.6 \mathrm{~kg}$ and $3.4 \mathrm{~kg}$, respectively. The carriage was released from height of up to $1.0 \mathrm{~m}$ and vertical columns were used to guide the descent of the carriage. The vertical guides of the 
impact tower were lubricated to minimize any friction generated during the descent of the carriage. The deforming mode of paper honeycomb sandwich is captured by using High-speed camera. Figure 4 shows the set up of High-speed camera in the drop impact test.

\section{RESULTS AND DISCUSSION}

\section{Low velocity impact of the Paper honeycomb sandwich}

Figure 5 shows the load-time history of the bar indentor for sandwich panel with different thicknesses. The curve shows that the first peak is the collapse load, $P_{c}$ of sandwich panel and followed by subsequent peaks. This might be due to the stiffness of skin and low strength of core material. Failure due to face yield, core shear, face wrinkling might also to produce the secondary peak and valley. The collapse load for $35 \mathrm{~mm}$ and $41 \mathrm{~mm}$ are $1055 \mathrm{~N}$ and $1378 \mathrm{~N}$, respectively. This indicates that the thicker the panel, the higher is the peak load. However, the form of Load-time curves is similar for both panels.

The failure processes in the impact-damaged sandwich panel were investigated by sectioning a number of samples through the High speed camera. Fig 6 shows the deforming mode of sandwich panel when bar indentor come into contact to the top face sheet. The both thickness failed as a result of a top surface buckling failure of the skin directly under the point of impact. Here, it is likely that the different thickness did not offer significant collapse load to the composite skin under impact loading conditions. As expected, an increase the thickness of sandwich from $35 \mathrm{~mm}$ to 41 $\mathrm{mm}$ resulted in an increase the collapse load.

The deformation and failure at core and facesheet of the paper honeycomb sandwich panel when load are applied can be observed using the Bar indentor as shown in Fig.7.

For the case of hemisphere indentor, Fig 8 shows the measured load-time history for the similar panel thicknesses (35 mm and $41 \mathrm{~mm})$. Fig 8 is associated with Fig 9 for deforming. This shows the collapse loads are almost the same value, with deviation less than $5 \%$. This might be due to the penetration of indentor, completely, in both top skin and core before reaching to the bottom skin. This can be seen at $t=0.006 \mathrm{~s}$ However, subsequent peaks and valleys might also due the crushing of core, progressively.

Fig.10 shows the penetration on the sandwich panel for the case of hemispherical indentor with $t=41 \mathrm{~mm}$ from the top skin.

The summary of results for dynamic loading is tabulated in Table 1. This also shows the comparison with quasi-static loading. The dynamic collapse load is higher in bar indentor compared with hemisphere indentor. The load shows from $755 \mathrm{~N}$ to $1052 \mathrm{~N}$ for the case of $35 \mathrm{~mm}$ and $723 \mathrm{~N}$ to $1377 \mathrm{~N}$ for the case of $41 \mathrm{~mm}$. However, the absolute value of dynamic collapse load is lower than quasi-static collapse load by 
$13 \%-23 \%$ for both thicknesses. This is not seen in bar indentor. This is due to bending failure.

However, in Table 1 shows the collapse load in hemispherical and bar indentors in $41 \mathrm{~mm}$ thickness are higher by $32 \mathrm{~N}(5 \%)$ and $325 \mathrm{~N}(24 \%)$, respectively when comparing with $35 \mathrm{~mm}$. The lower goes hemispherical indentor due to penetration completely. It is not seen in bar indentor. Comparing with quasi-static result in 35 $\mathrm{mm}$ thickness [9], the energy absorbed in dynamic increases by $36 \%$. The same also goes for $41 \mathrm{~mm}$. This may be due to the effect of strain rate.

\section{CONCLUSIONS}

Paper Honeycomb sandwich panel; Nomex honeycomb core and woven carbon prepregs skin with different thicknesses under low velocity impact using two different indentor (hemispherical and bar) are studied and presented. The hemispherical indentor shows the penetration compared with bar indentor. The collapse load in 41 $\mathrm{mm}$ thickness increases by $5 \%$ for hemispherical indentor and $24 \%$ for bar indentor. The experimental result shows that the impact energy absorbed for hemispherical indentor increases by $36 \%$.

\section{ACKNOWLEDGEMENT}

The authors would like to thank University Teknikal Malaysia Melaka and Ministry of Higher Education, Malaysia for providing the support and fund for accomplishment of this project. The project is funded under Fundamental Research Grant Scheme, FRGS/2010/FKM/TK01/8- F 00096

\section{REFERENCES}

[1] M. Yang, P. Qiao. "Quasi-static indentation behavior of honeycomb sandwich materials and its application in impact simulations". J. Aerosp. Engineering. Volume 21, Issue 4, pp. 226-234 (2008).

[2] Barboutis I. and V. Vassiliou. "Strength properties lightweight paper honeycomb panels for furniture" Proceedings of International Scientific Conference 10th Anniversary of Engineering Design (Interior and Furniture Design). pp17-18 (2005)

[3] V. Crupi and R. Montanini. "Aluminium foam sandwiches collapse modes under static and dynamic three-point bending". International Journal of Impact Engineering 34, pp 509-521 (2007).

[4] Joem Kee Paik, Anil K. Thayamballi and Gyu Sung Kim. "The strength characteristics of aluminum honeycomb sandwich panels". Thin-Walled Structures 35, pp 205-231 (1999).

[5] Eric J. Herup and Anthony N. Palazotto. "Low velocity impact damage in graphite/epoxy/nomex honeycomb-sandwich plates". Composite Science and Technology 53, pp 1581-1598 (1997). 
[6] L. Gibson, M. F. Ashby-"Cellular solids--Structures and Properties--second edition", Published by the Press Syndicate of the University of Cambridge, (1997).

[7] Md. Akil Hazizan and W.J. Cantwell. "The low velocity impact response of foambased sandwich structures". Composites Part B: Engineering 33, pp 193-204 (2002).

[8] Md. Akil Hazizan and W.J. Cantwell. "The low velocity impact response of an aluminium honeycomb sandwich structure". Composites Part B: Engineering 34, pp 679-687 (2003).

[9] Said, M.R., Ismail, M. K, and Syed Putra S.A " Paper honeycomb sandwiche panels under static 3-point bending" Proceeding of International Conference and Exhibition Sustainable Energy and Advanced material, Solo, 3-4 Oct 2011, pp271-278 (2011).

\section{Figures:}

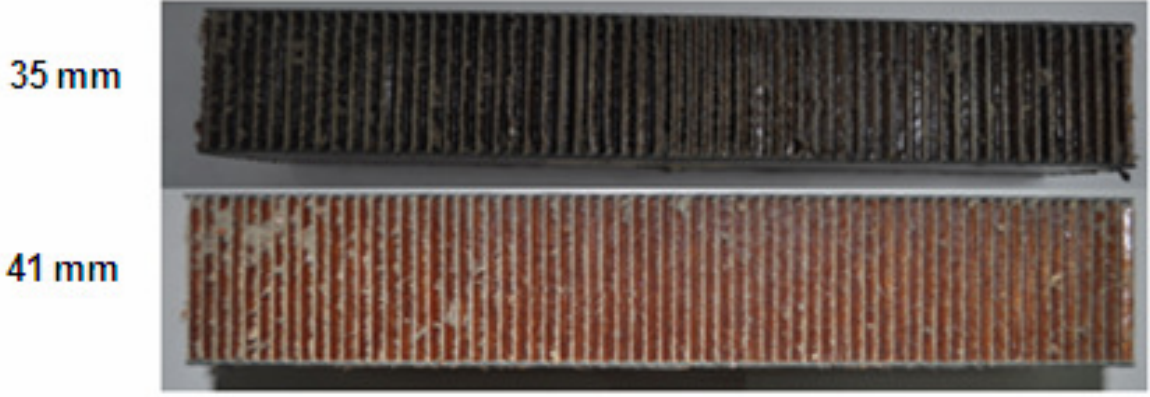

Fig. 1. Sample of the paper honeycomb sandwich panel with thickness of $35 \mathrm{~mm}$ and $41 \mathrm{~mm}$.
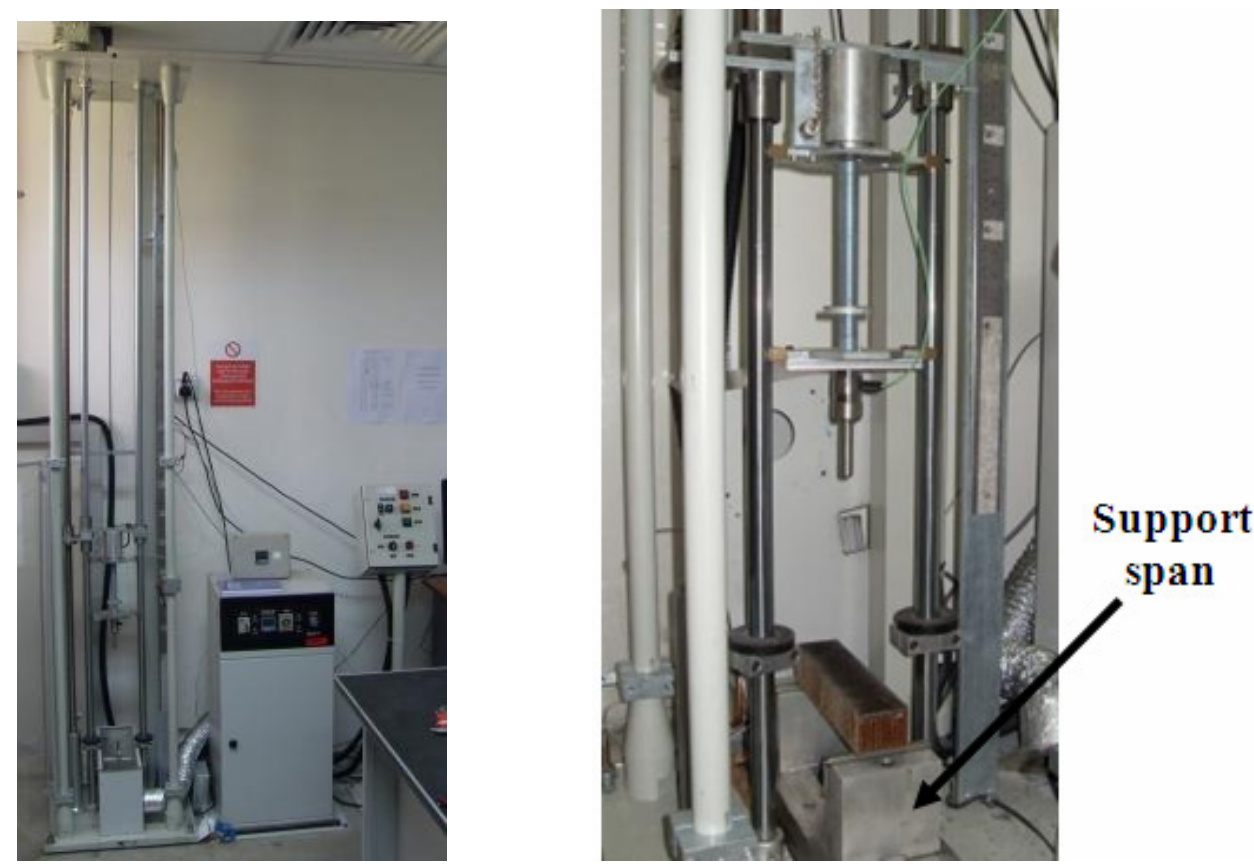

Fig. 2. (a) Falling weight impact tower (b) Experimental setup of drop impact. 
(a)

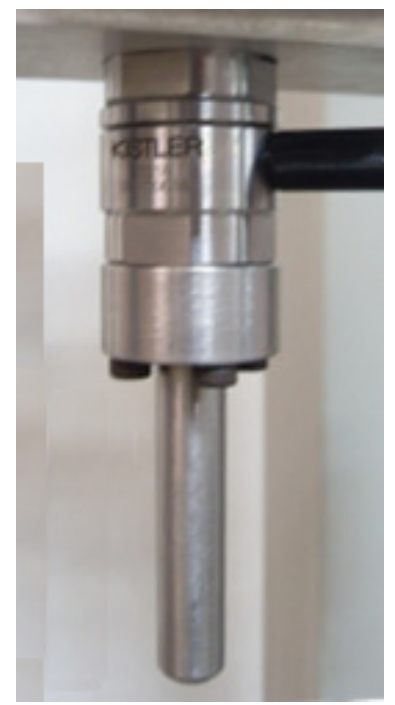

(b)

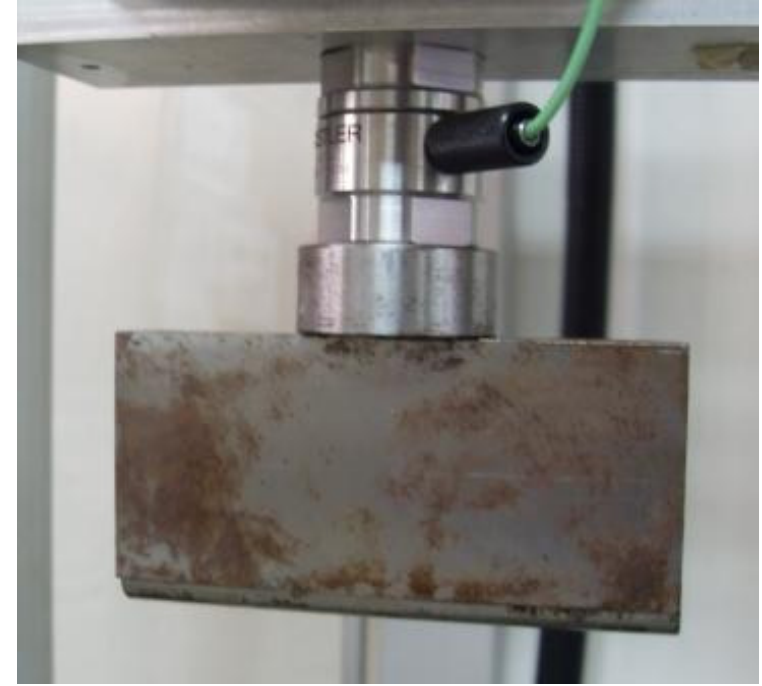

Fig. 3. (a) Hemispherical indentor, (b) Bar indentor.

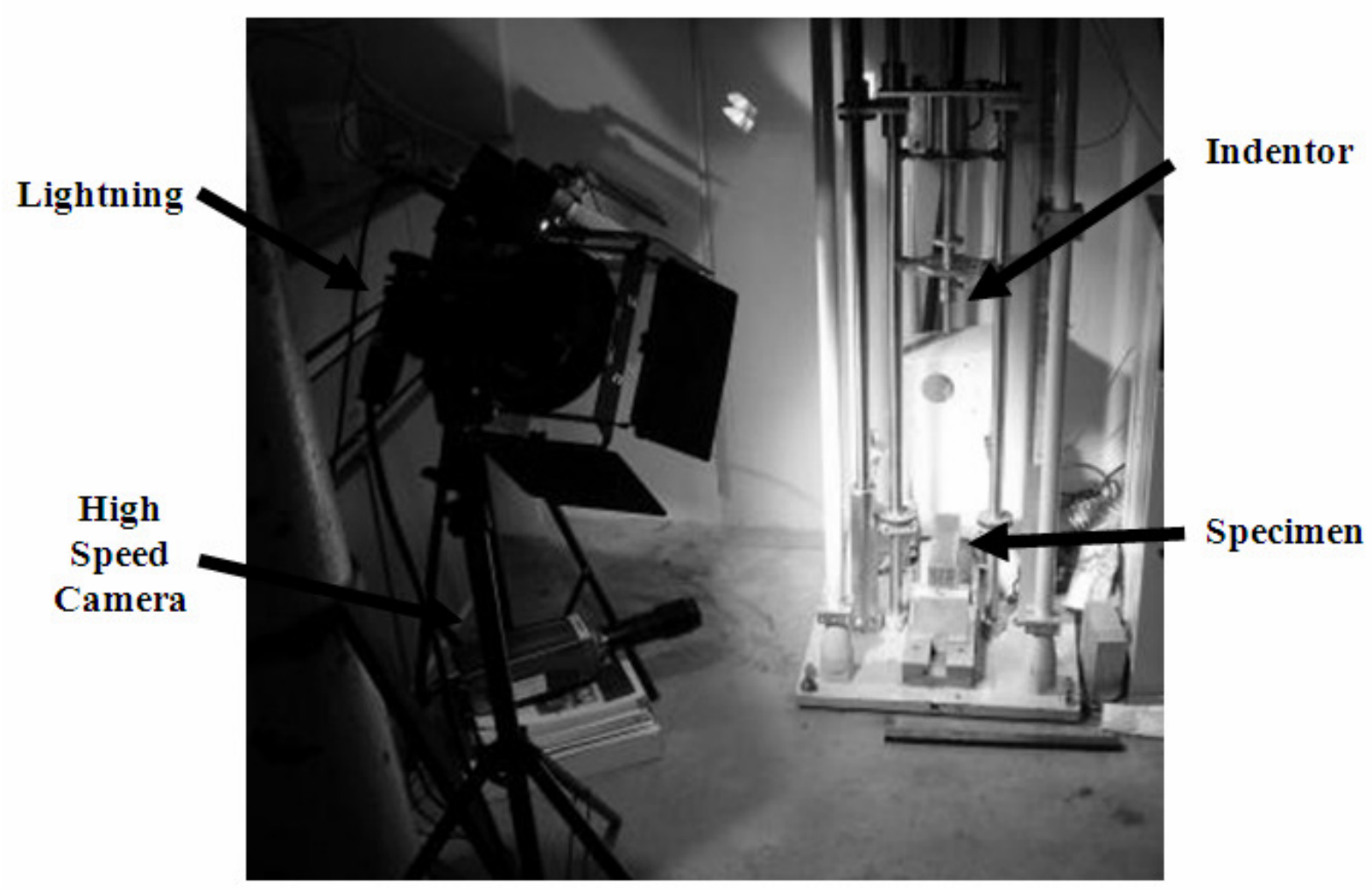

Fig. 4. High-speed camera set up. 


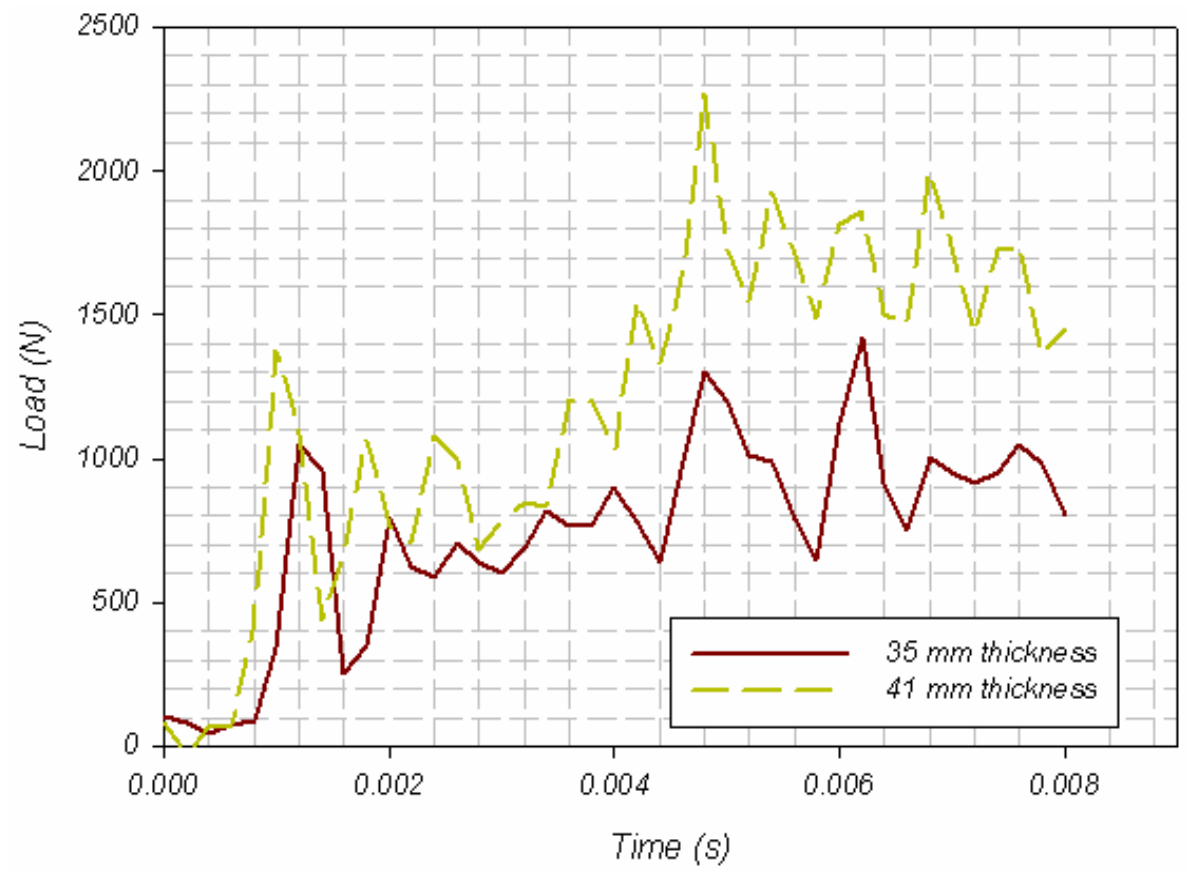

Fig. 5. Load-time history due to the pierce of bar indentor into different thicknesses of panels.

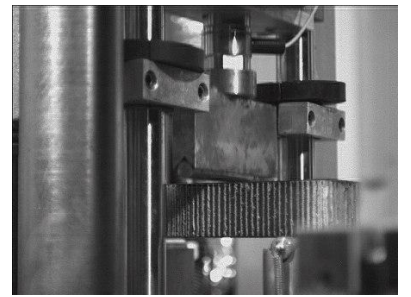

$0.000 \mathrm{~s}$

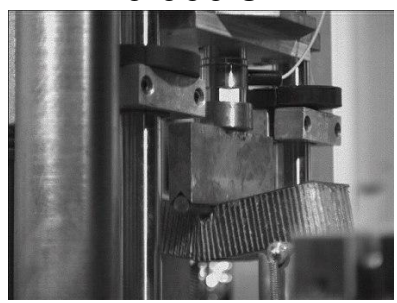

$0.003 \mathrm{~s}$

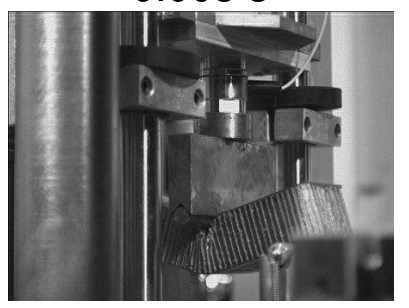

$0.006 \mathrm{~s}$

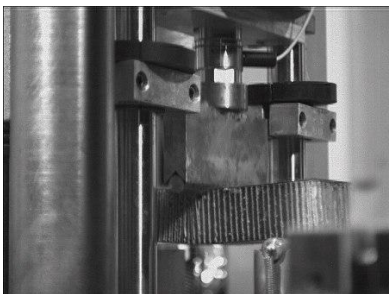

$0.001 \mathrm{~s}$

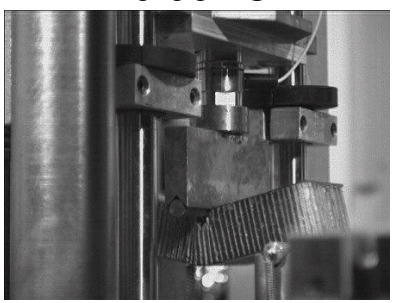

$0.004 \mathrm{~s}$

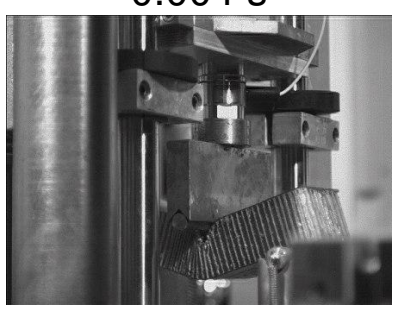

$0.007 \mathrm{~s}$

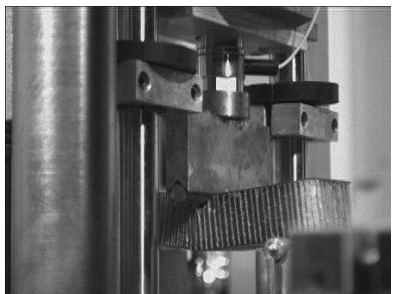

$0.002 \mathrm{~s}$

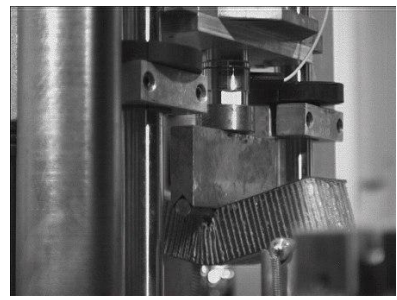

$0.005 \mathrm{~s}$

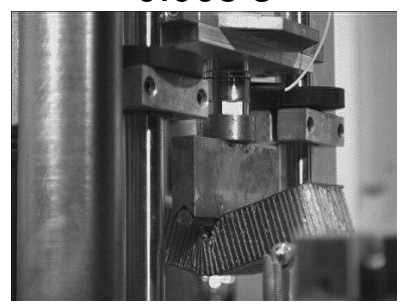

$0.008 \mathrm{~s}$

Fig. 6. The deforming mode using Bar indentor for $35 \mathrm{~mm}$ thickness. 


\section{Deformation and line at}

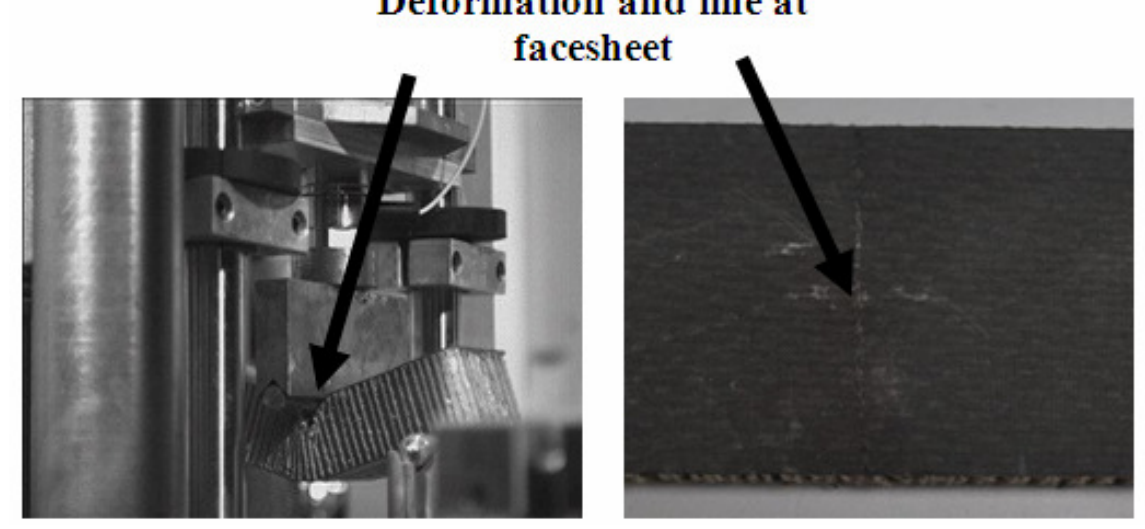

Fig. 7. The deformed honeycomb sandwich panel using bar indentor.

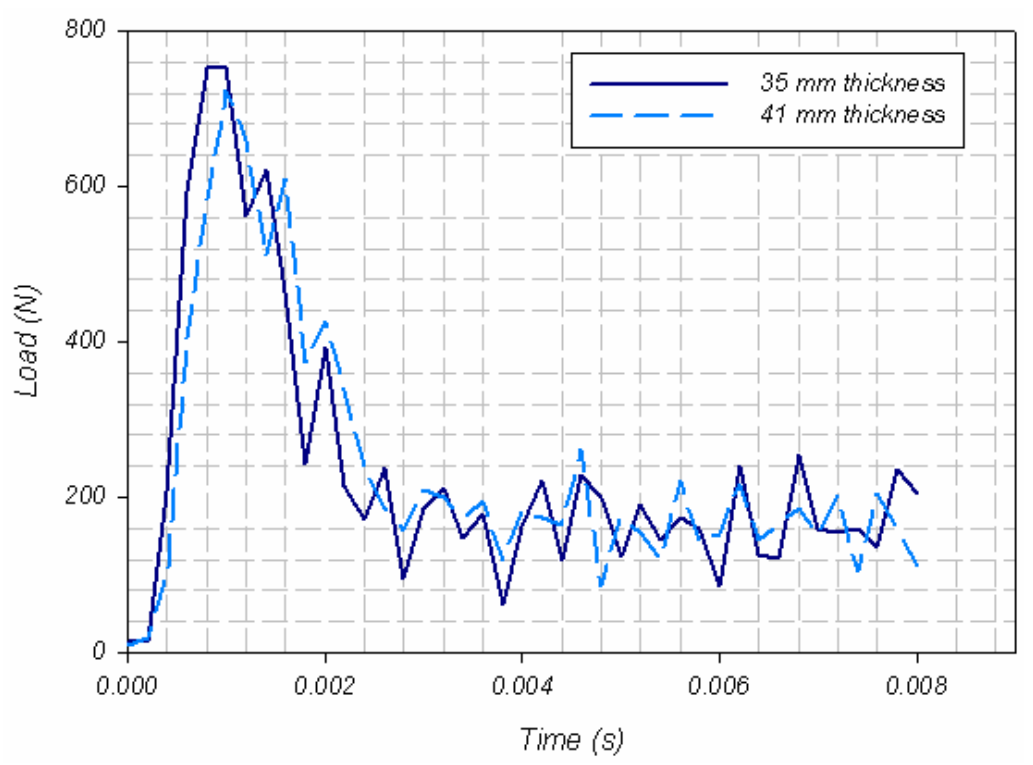

Fig. 8. Graph Load against Time for Hemisphere indentor. 


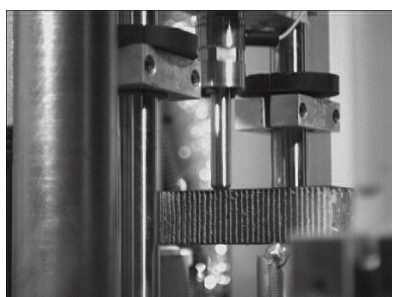

$0.000 \mathrm{~s}$

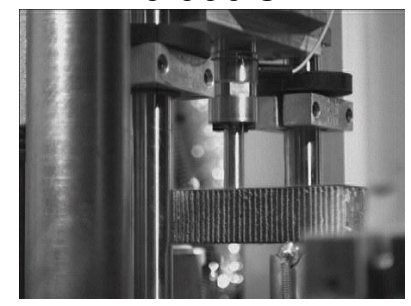

$0.003 \mathrm{~s}$

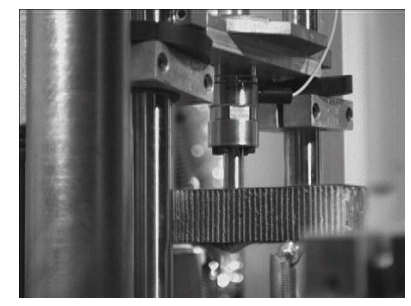

$0.006 \mathrm{~s}$

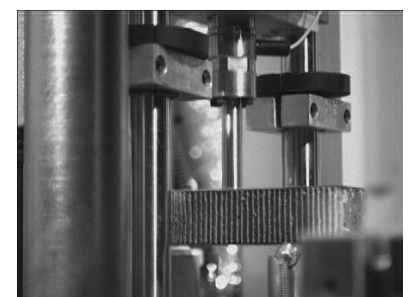

$0.001 \mathrm{~s}$

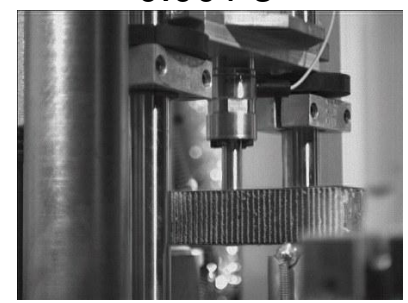

$0.004 \mathrm{~s}$

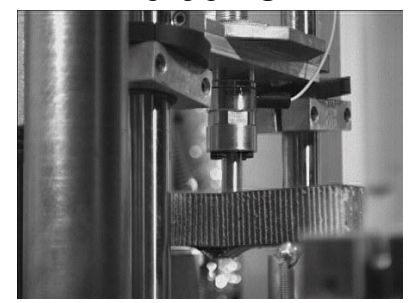

$0.007 \mathrm{~s}$

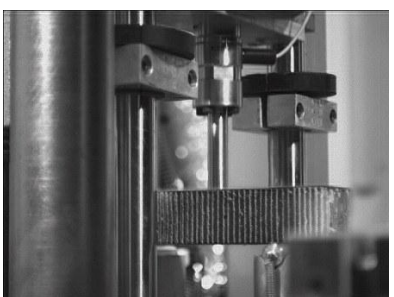

$0.002 \mathrm{~s}$

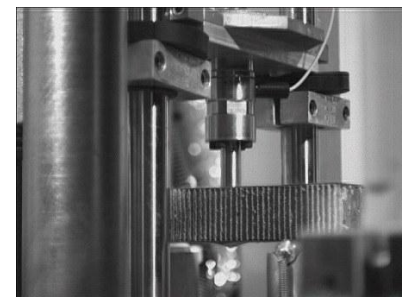

$0.005 \mathrm{~s}$

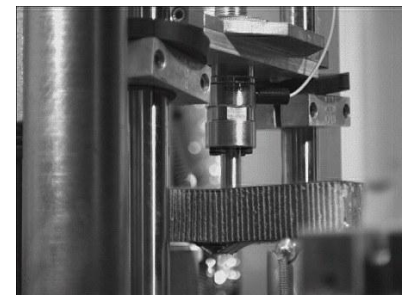

$0.008 s$

Fig. 9. The deforming mode Hemisphere indentor for $35 \mathrm{~mm}$ thickness.

\section{Penetration honeycomb} sandwich
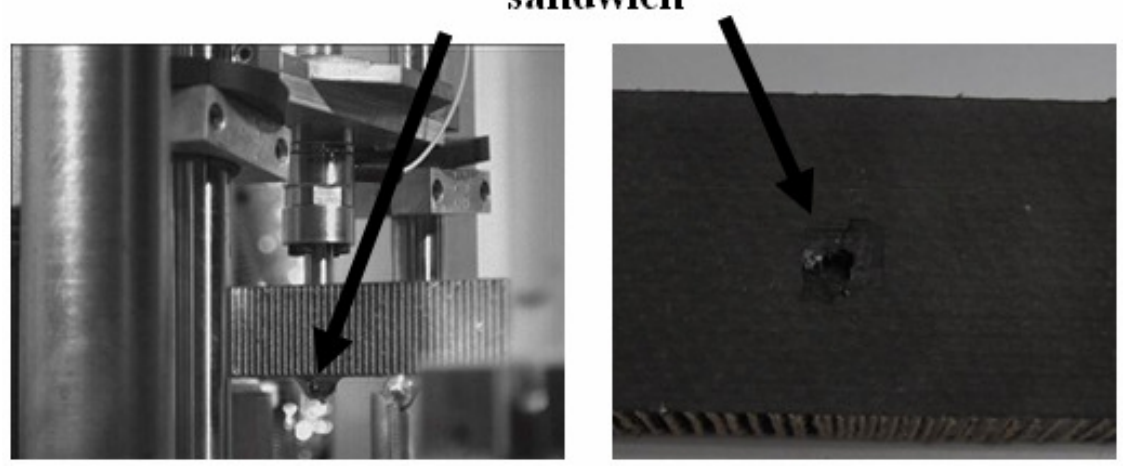

Fig. 10. Hemispherical indentor penetration the Honeycomb sandwich 
Table 1. Experimental results for dynamic loading.

\begin{tabular}{|c|c|c|c|c|}
\hline Experimental & \multicolumn{4}{|c|}{$\begin{array}{c}\text { Dynamic Loading (Low } \\
\text { velocity impact 3 point } \\
\text { bending) }\end{array}$} \\
\hline Indentor & Hemispherical & \multicolumn{2}{|c|}{ Bar } \\
\hline $\begin{array}{c}\text { Sample } \\
\text { thickness } \\
\text { (mm) }\end{array}$ & $\begin{array}{c}\mathbf{3 5} \\
\mathbf{m m}\end{array}$ & $\begin{array}{c}\mathbf{4 1} \\
\mathbf{m m}\end{array}$ & $\begin{array}{c}\mathbf{3 5} \\
\mathbf{m m}\end{array}$ & $\begin{array}{c}\mathbf{4 1} \\
\mathbf{m m}\end{array}$ \\
\hline $\begin{array}{c}\text { Collapse load, } \\
\boldsymbol{P}_{\boldsymbol{c}} \text { (N) }\end{array}$ & 723 & 755 & 1052 & 1377 \\
\hline $\begin{array}{c}\text { Energy } \\
\text { absorbed, } \boldsymbol{E} \\
\text { (Nm) at up to } \\
\text { collapse load }\end{array}$ & 0.34 & 0.38 & 0.51 & 0.64 \\
\hline
\end{tabular}

